\title{
Utility of stages of change construct in the planning of physical activity interventions among playgroup mothers
}

Carlie Jones ${ }^{1,2^{*}}$, Jonine Jancey ${ }^{1,2}$, Peter Howat ${ }^{1,2}$, Satvinder Dhaliwal ${ }^{1,2}$, Sharyn Burns ${ }^{1}$, Alexandra McManus ${ }^{3}$, Andrew P Hills ${ }^{4}$ and Annie S Anderson ${ }^{5}$

\begin{abstract}
Background: The objective of this research was to assess the physical activity levels among a unique cohort of Western Australian (WA) mothers with young children who attend a WA Playgroup. Associated factors were also investigated, including self-efficacy for physical activity, social support for exercise, relevant socio-demographic correlates, as well as the stages of change construct within the Transtheoretical Model (TTM).

Results: 421 women completed a questionnaire assessing physical activity behaviours. Of these, 368 participants completed the relevant physical activity evaluation items. $82.5 \%$ and $17.5 \%$ of the sample were classified as active and inactive, respectively. Associations between physical activity status and exercise stage of change were found. Additional associations were established for partner support and self-efficacy for physical activity.

Conclusion: The majority of the sample was classified as active. Despite the high percentage of active participants, this study confirms the usefulness of the stages of change measure in that it can be utilised by health promotion practitioners to report physical activity behaviour and develop appropriate intervention strategies among a time poor and hard to reach population. Specifically the results are relevant to mothers in over 16,000 WA families who are involved with Playgroup WA programs. Interventions aimed at improving physical activity levels in mothers with young children should also consider the need to improve self-efficacy and social support.
\end{abstract}

Keywords: Physical activity, Mothers, Stages of change, Exercise

\section{Background}

Adverse health outcomes directly related to low levels of physical activity [1] are well recognised with the World Health Organization (WHO) listing physical inactivity as the fourth highest risk factor contributing to mortality on a global scale [2]. As a means of reducing the risk of chronic disease, the National Physical Activity Guidelines for Adults (1999) recommend Australians accumulate a minimum of 30 minutes of physical activity at a moderate-intensity level on most days of the week [3]. This guideline is also supported by WHO (2010) which recommends adults participate in aerobic activity at a

\footnotetext{
* Correspondence: Carlie.Jones@curtin.edu.au

${ }^{1}$ Western Australian Centre for Health Promotion Research, School of Public

Health, Curtin University, Western Australia, Perth, Australia

${ }^{2}$ Centre for Behavioural Research in Cancer Control, Curtin University,

Western Australia, Perth, Australia

Full list of author information is available at the end of the article
}

moderate-intensity level for at least 150 minutes each week [2]. Alternatively, adults can complete at least 75 minutes of aerobic activity at a vigorous-intensity level, or a comparable amalgamation of both [2]. The 2008 physical activity guidelines for Americans mirror that of the WHO [4].

The need to achieve and maintain the recommended levels of physical activity is particularly relevant to women in the childbearing years [5]. Research indicates that this period is commonly associated with an increase in body weight and can lead to women experiencing long-term overweight and obesity [6,7]. Studies reporting on postpartum weight indicate that on average, women tend to lose weight up until 12-months post-partum [8,9], then increase their weight after this period [8]. This increase in weight following the initial weight loss period has been attributed to an increase in body fat $[9,10]$, commonly 
caused by an energy imbalance where there is an increase in energy consumption and inadequate physical activity $[9,11]$.

Physical activity behaviours of women during the reproductive years are less than optimal, with $75.3 \%$ of Australian females aged 18 to 44 years in 2007-8 classified as having low or sedentary levels of physical activity [12]. Among Australian women in this age category, only $19.1 \%$ and $5.6 \%$ were classified as having moderate and high levels of physical activity, respectively [12]. Miller et al. [13] noted that among Australian women aged 18 to 22 years, only $46 \%$ of those with children participated in sufficient levels of physical activity compared to $56 \%$ of those without children. Internationally in 2007 , similar results were reported with only $51.6 \%$ of women aged 18 to 44 years in the United States of America achieving the recommended physical activity levels [14].

Many women undergo changes when they become mothers with their physical activity habits often shifting from being structured and intense to incidental and less intense [15]. Women with children also reported that it was more difficult to pursue physical activity for leisure and transport than women without children [16]. Nevertheless, women with children did express that physical activity associated with completing domestic duties was considered to be more manageable.

Mothers with young children, particularly those who were married and did not work outside the family home, were more likely to be classified as inactive [17]. Many barriers have been cited as preventing mothers from participating and maintaining adequate physical activity levels [15] including feelings of fatigue [15,18], and a perceived lack of time $[15,18,19]$ and motivation $[15,19]$. Mothers also reported difficulty in managing the demands involved in raising young children such as organising their children's sleep and feeding times around their personal physical activity $[15,18,20]$. Feelings of guilt associated with mothers taking time to exercise were also reported as a major barrier along with a change in priorities $[15,21,22]$. Commonly, mothers often prioritised their family's needs before their own [15].

As mothers are primary role models for their offspring it is important that they maintain sufficient levels of physical activity not only for their continuing health and wellbeing but also for their children's. Moore et al. [23] reported that children of active mothers were twice as likely to be active when compared to children with inactive mothers. Similarly, Hesketh et al. [24] reported that mothers who were more active, had greater intentions and self-efficacy for encouraging active play with their young children.

The aim of this paper was to assess the physical activity levels among a unique cohort of Western Australian (WA) mothers with young children who attended a WA Playgroup. The playgroup setting provides an avenue to reach over 16,000 WA families who are involved with Playgroup WA.

Specifically, this study analysed a component of a health behaviour change model and factors associated with physical activity levels. This involved an investigation of the stages of change construct within the Transtheoretical Model (TTM) [25-27] and reported levels of physical activity. Self-efficacy $[28,29]$ and social support [13], along with relevant socio-demographic correlates, were also analysed.

\section{Methods}

\section{Participants}

Mothers with young children were recruited from WA playgroups registered with Playgroup WA (Inc) located within 20 kilometres of the Perth metropolitan area. Playgroup WA (Inc) supports community playgroups that offer opportunities for families with young children to play and learn in a fun and informal setting. Participants were required to have a basic proficiency in spoken English and to be the primary female caregiver of a child attending a registered playgroup. Individuals were excluded from the study if they had a medical condition that may have contraindicated their participation in the study, and/or were less than 18 years of age. In total, 421 women completed a base-line questionnaire that assessed dietary and physical activity habits. Of these, 368 participants completed the questions assessing physical activity levels. Ethics approval was granted by the Human Research Ethics Committee at Curtin University prior to the commencement of the study (HR171/2006).

\section{Procedure}

Each playgroup was managed by a Playgroup Leader, a mother who volunteers to be responsible for the management of the playgroup. The Playgroup Leaders were contacted and invited to participate. As each playgroup varied in the number of playgroup sessions, the invited participants attended the session managed by the leader. An information sheet, consent form and self-report questionnaire were then provided to each consenting participant. Pre-paid return envelopes were provided to allow each participant to return their completed questionnaire.

\section{Measures}

Questions regarding physical activity were derived from the International Physical Activity Questionnaire-Short Version (IPAQ-SV) [30] and items used by the WA Department of Health [31]. The self-report instrument enabled physical activity via walking to be assessed and separated into the domains of walking for errands and transport, and for recreation and exercise. All other forms of physical activity were included as moderate and vigorous-intensity physical activity. Moderate-intensity physical activity was defined as '...activities that take moderate physical effort 
and make you breathe somewhat harder such as swimming, jogging, cycling, lifting light loads or housework' [30]. Vigorous-intensity physical activity was defined as '....activities that take hard physical effort and make you breathe much harder than normal such as heavy lifting, digging, aerobics and fast cycling or running' [30]. Only activities that were completed for at least 10 minutes continuously were included. Physical activity levels for each participant were then calculated based on the methods recommended by Brown and Bauman [32] and replicated by Bell and Lee [17]. This involved an indirect assessment of energy expenditure where the metabolic equivalent of task (MET) was multiplied by the length of the physical activity in minutes [32]. The calculation used for each participant included multiplying the reported minutes of walking by three MET, moderate activity by four metabolic units, and vigorous activity by $7.5 \mathrm{MET}$ and then totalling the final three figures thus creating a MET.mins score [17]. Based on the calculated score, participants were categorised as either inactive with a score of 599 or lower, and active if they had a score of 600 or more [17]. A score of 600 or more is equivalent to at least 30 minutes of daily moderateintensity activity on five days over the course of a week [32], a level of activity reported to be adequate for health benefits $[2,3]$. The use of this method is reported to reduce the risk of underestimating the physical activity levels among women [32]. Using the same calculation method, a second definition for physical activity status was determined and used to categorise participants above or below the median physical activity score of 1395.

The stage of change construct within the TTM is commonly used to identify an individual's stage in regard to their physical activity participation [25-27]. The exercise stage of change construct provides a series of stages that people can move through sequentially as well as intermittently. The five stages of change within the construct typically include pre-contemplation (Stage one, I currently do not exercise and I do not intend to start exercising in the next six months), contemplation (Stage two, I currently do not exercise but I am thinking about starting to exercise in the next six months), preparation (Stage three, I currently exercise but not regularly), action (Stage four, I currently exercise regularly but I have only begun to do so within the past six months) and maintenance (Stage five, I currently exercise regularly and I have done so for longer than six months) $[33,34]$. These stages were included in the current study along with the addition of a relapse stage (Stage six, I have exercised in the past but I am not doing so currently) [35].

Physical activity self-efficacy was assessed using a modified version of the McAuley Self-efficacy for exercise scale [36] as well as additional items used by Miller et al. [13] that are specific to mothers with young children. In total 17 items were used to assess exercise self-efficacy. A score was calculated by summing the score from each of the 17 items and then dividing the total by 17 .

Partner support and family/friend support for exercise were measured using items from Sallis (1987) and Miller et al. (2002) [13,37]. Two sets of five items were used to assess each type of support (partner support and friend/ family support). An overall score for both partner support and family/friend support was calculated based upon the mean response over the five items. A higher score for example reflected greater support in that domain.

Socio-demographic items used by the Australian Bureau of Statistics were also included in the analysis. These included mother's age, marital status, household income, employment status, education status, country of origin, socio-economic level (SES) [38] (as determined by socioeconomic indexes (SEIFA) for area) and parity. In addition measures of body mass index (BMI), breastfeeding and pregnancy status were included.

\section{Statistical analysis}

The representativeness of the study sample was assessed by comparing the demographics to the Perinatal Statistics in Western Australia 2008 report [39] using the chi-square goodness-of-fit test. The association between personal, behavioural and socio-demographic factors, and activity status were assessed using chi-square test, logistic regression and independent samples t-tests. Activity status was defined in two ways: active and not active; below and above median. P-values $<0.05$ were considered to be statistically significant. The data was analysed using Statistical Package for Social Sciences (SPSS, Version 18).

\section{Results}

\section{Sample demographics}

The mean age of the participants was 34.6 years (range 2147 years). Among the sample, $73 \%(n=299)$ had more than one child; 97\% ( $n=406)$ were married; $69 \%(n=291)$ were born in Australia and 58\% ( $\mathrm{n}=246)$ were not working outside the home at the time of the study. The demographics of the study sample were compared to the WA Perinatal Statistics in Western Australia 2008 demographic data [39] (Table 1). The study sample was representative for country of origin and area of residence. Statistically significant differences between the study sample and the Perinatal Statistics in Western Australia were observed for the variables mothers' age, marital status, parity and socio-economic differences. The current study sample had a greater proportion of women who were older, married, had two or three children and came from a higher socio-economic level.

\section{Associations of personal, behavioural and socio-demographic factors with level of activity}

The physical activity status (using the active or inactive definition) of study participants was compared with the 
Table 1 A comparison of the sample demographics with the perinatal statistics in Western Australia 2008 report [39]

\begin{tabular}{lrr}
\hline Demographics & $\begin{array}{r}\text { Study sample } \\
(\mathbf{N}=\mathbf{4 2 1})\end{array}$ & $\begin{array}{r}\text { Perinatal statistics in Western } \\
\text { Australia 2008 (N=30,234) }\end{array}$ \\
\hline Mother's age in years & & \\
$18-24$ & $6(1.5 \%)$ & $5882(19.8 \%)$ \\
$25-29$ & $48(11.7 \%)$ & $8162(27.4 \%)$ \\
$30-34$ & $134(32.5 \%)$ & $9211(30.9 \%)$ \\
$35-39$ & $174(42.2 \%)$ & $5475(18.4 \%)$ \\
$40-44$ & $45(10.9 \%)$ & $993(3.3 \%)$ \\
$45+$ & $5(1.2 \%)$ & $39(0.1 \%)$ \\
\hline
\end{tabular}

Country of origin

$\begin{array}{llr}\text { Australia } & 291(69.3 \%) & 20852(71.1 \%) \\ \text { Other } & 129(30.7 \%) & 8471(28.9 \%)\end{array}$

\begin{tabular}{lrr}
\hline Marital status & & \\
Married / Defacto & $406(97.1 \%)$ & $27137(89.8 \%)$ \\
Other & $12(2.9 \%)$ & $3097(10.2 \%)$ \\
\hline Parity & & \\
1 child & $113(27.4 \%)$ & $12478(41.3 \%)$ \\
$2-3$ children & $286(69.4 \%)$ & $14830(49.1 \%)$ \\
$4-5$ children & $13(3.2 \%)$ & $2387(7.9 \%)$ \\
$6+$ & $0(0 \%)$ & $539(1.8 \%)$ \\
\hline
\end{tabular}

Area of residence (WA)

\begin{tabular}{lrr} 
North metropolitan & $226(53.6 \%)$ & $12118(52.5 \%)$ \\
South metropolitan & $196(46.4 \%)$ & $10942(47.5 \%)$ \\
\hline Socio-economic quintile & & \\
I & $93(22.6 \%)$ & $7268(24.5 \%)$ \\
II & $125(30.3 \%)$ & $4382(14.7 \%)$ \\
III & $92(22.3 \%)$ & $5840(19.7 \%)$ \\
IV & $46(11.2 \%)$ & $6431(21.6 \%)$ \\
V & $56(13.6 \%)$ & $5792(19.5 \%)$ \\
\hline
\end{tabular}

\section{Education}

\begin{tabular}{lr} 
Completed year 10 & $19(5 \%)$ \\
Completed year 11 & $16(4 \%)$ \\
Completed year 12 & $47(11 \%)$ \\
TAFE/Diploma & $112(26 \%)$ \\
University degree & $212(50 \%)$ \\
Other & $13(3 \%)$ \\
\hline
\end{tabular}

\section{Employment}

\begin{tabular}{lr} 
Part-time & $114(27 \%)$ \\
Full-time & $6(1 \%)$ \\
Casual & $45(11 \%)$ \\
Student & $8(2 \%)$ \\
$\begin{array}{l}\text { Currently not working } \\
\text { outside the home }\end{array}$ & $246(58 \%)$ \\
\hline
\end{tabular}

Note: Socio-economic quintiles are based on the index of relative socio-economic advantage and disadvantage produced by the Australian Bureau of Statistics, 2008 [38]. Group V depicts the lowest socio-economic status and group I represents the highest [39]. following variables (Table 2): mother's age, marital status, level of education, employment status, household income, parity, country of origin, socio-economic level, BMI, and breastfeeding and pregnancy status. Using the chi-square goodness-of-fit test, there were no statistically significant differences $(P>0.05)$ between active and inactive mothers nor between mothers above and below the median physical activity score.

When comparing physical activity status with the exercise stage of change variable, the logistic regression analysis indicated that stages three to six were significantly different from stage one (pre-contemplation) $(\mathrm{P}<0.01)$. Participants who were in stage three (preparation), stage four (action) and stage five (maintenance) were respectively 6.17 (95\% CI: 1.76 - 21.81), 15.2 (95\% CI: 3.75 61.55), and 36.8 (95\% CI: 8.79 - 154.06) times more likely to be categorised as being active compared to those in stage one. Furthermore, participants who were in the relapse stage (stage six) were 6.1 (95\% CI: 1.63 - 22.69) times more likely to be categorised as being active compared to those who were in the pre-contemplation stage. Associations with exercise stage of change and participants being above the median physical activity score (Audit score $=1395$ ) were also found. Participants in stage four and five were 10.3 (95\% CI: 2.08 - 50.42) and 10.2 (95\% CI: 2.16 - 48.25) times more likely than participants in stage one to be above the median physical activity score. Figure 1 illustrates the percentiles of the sample within each stage of the construct.

Using independent samples $t$-tests, the results also demonstrated that participants' self-efficacy and partner support scores was significantly associated with activity status when using both definitions for physical activity status $(\mathrm{P}<0.05)$ (active and not active; below and above median). Social support from friends and other family members, was statistically significant when using the 'below and above the median' definition $(\mathrm{P}<0.05)$.

\section{Discussion}

This study covered a diverse sample of WA mothers with young children that included a greater proportion of women who were older, married, had two or more children and came from a higher socio-economic level when compared to a representative sample of WA mothers [39]. Physical activity status among participants was not statistically associated with level of education, income status, parity, SEIFA index, pregnancy and breastfeeding status or BMI when using both definitions for physical activity status. Interestingly, the current study showed no associations with marital status and employment, unlike Bell and Lee [17] who indicated that among a representative sample of 8545 Australian women, having children, being married and carrying out domestic duties full time was strongly linked to low levels of physical activity. They also 
Table 2 A comparison of active and inactive participants

\begin{tabular}{lrr}
\hline Demographics & Inactive (N=64) & Active (N=304) \\
\hline Mother's age in years & $9(14.3 \%)$ & $37(12.4 \%)$ \\
$18-29$ & $44(69.8 \%)$ & $228(76.5 \%)$ \\
$30-39$ & $10(15.9 \%)$ & $33(11.1 \%)$ \\
$40+$ & & \\
\hline Country of origin & $46(71.9 \%)$ & $209(69 \%)$ \\
Australia & $18(28.1 \%)$ & $94(31 \%)$ \\
Other & & \\
\hline Marital status & $56(88.9 \%)$ & $264(87.4 \%)$ \\
Married / Defacto & $7(11.1 \%)$ & $38(12.6 \%)$ \\
Other & & \\
\hline Parity & $16(26.2 \%)$ & $82(27.3 \%)$ \\
1 child & $45(73.8 \%)$ & $218(72.7 \%)$ \\
$2+$ & & \\
\hline Socio-economic quintile & $36(57.1 \%)$ & $166(56.1 \%)$ \\
I & $12(19 \%)$ & $51(17.2 \%)$ \\
II & $4(6.3 \%)$ & $23(7.8 \%)$ \\
III & $8(12.7 \%)$ & $42(14.2 \%)$ \\
IV & $3(4.8 \%)$ & $14(4.7 \%)$ \\
V & &
\end{tabular}

\section{Education}

\begin{tabular}{lrr} 
Never attend, year 7-12 or other & $16(25 \%)$ & $65(21.5 \%)$ \\
TAFE/Diploma & $11(17.2 \%)$ & $81(26.8 \%)$ \\
University degree & $37(57.8 \%)$ & $156(51.7 \%)$ \\
\hline Income & & \\
$<\$ 18,200$ to $\$ 51,999$ & $7(11.1 \%)$ & $31(10.6 \%)$ \\
$\$ 52,000$ to $\$ 62,339$ & $6(9.5 \%)$ & $12(4.1 \%)$ \\
$\$ 62,400$ to $\$ 72,799$ & $6(9.5 \%)$ & $35(11.9 \%)$ \\
$\$ 72,800$ to $\$ 88,399$ & $6(9.5 \%)$ & $34(11.6 \%)$ \\
\$88,400 to \$103,999 & $13(20.6 \%)$ & $52(17.7 \%)$ \\
\$104,000 to \$129,999 & $13(20.6 \%)$ & $51(17.4 \%)$ \\
$>$ >130,000 & $12(19 \%)$ & $78(26.6 \%)$ \\
\hline BMI & & \\
Underweight $(<18.5)$ & $1(1.6 \%)$ & $10(3.6 \%)$ \\
Healthy Weight $(18.5-24.9)$ & $34(55.7 \%)$ & $142(50.9 \%)$ \\
Pre-obese $(25-29.9)$ & $9(14.8 \%)$ & $68(24.4 \%)$ \\
Obese I (30-34.9) & $6(9.8 \%)$ & $28(10 \%)$ \\
Obese II (35-39.9) or Obese III (>40) & $3(4.9 \%)$ & $6(2.2 \%)$ \\
\hline
\end{tabular}

\section{Employment}

Part-time or full-time

Casual, student or not working

\section{Pregnancy status}

$\begin{array}{lrr}\text { Pregnant } & 9(14.1 \%) & 25(8.3 \%) \\ \text { Not pregnant } & 55(85.9 \%) & 278(91.7 \%)\end{array}$

Table 2 A comparison of active and inactive participants (Continued)

\begin{tabular}{lcr}
\hline $\begin{array}{l}\text { Breastfeeding status } \\
\text { Breastfeeding }\end{array}$ & $9(14.1 \%)$ & $67(22.1 \%)$ \\
Not breastfeeding & $5(85.9 \%)$ & $236(77.9 \%)$ \\
\hline $\begin{array}{l}\text { Exercise stage of change } \\
\text { Stage } 1 \text { (Pre-contemplation) }\end{array}$ & $8(12.5 \%)$ & $5(1.7 \%)$ \\
Stage 2 (Contemplation) & $21(32.8 \%)$ & $33(10.9 \%)$ \\
Stage 3 (Preparation) & $14(21.9 \%)$ & $54(17.9 \%)$ \\
Stage 4 (Action) & $6(9.4 \%)$ & $57(18.9 \%)$ \\
$\begin{array}{l}\text { Stage } 5 \text { (Maintenance) } \\
\text { Stage 6 (Relapse) }\end{array}$ & $5(7.8 \%)$ & $115(38.1 \%)$ \\
\hline $\begin{array}{l}\text { Note: Socio-economic quintiles are based on the index of relative } \\
\text { socio-economic advantage and disadvantage produced by the Australian } \\
\text { Bureau of Statistics, 2008 [38]. Group V depicts the lowest socio-economic } \\
\text { status and group I represents the highest [39]. }\end{array}$ &
\end{tabular}

reported that when analysing their data over time, moving in with a partner, getting married and having children was associated with reduced levels of physical activity. It is probable that the high percentage of women in the current study classified as being active is the reason for the lack of association with demographic variables; with $82.5 \%$ and $17.5 \%$ of the study sample classified as active and inactive, respectively. These figures represent higher physical activity levels than reported by the Australian Bureau of Statistics [12]. The high percentage of active women in the current study could be related to physical activity levels being overestimated when using the IPAQ-SV [40]. The majority of the sample in this study also self-reported a healthy BMI and a high SES status which could further explain the high levels of physical activity reported.

The age of women has previously been linked to the reported level of physical level [32]. Brown and Bauman [32] used MET.mins to calculate activity level and found that only $55.4 \%$ of women aged $30-44$ years were adequately active, while $68.3 \%$ of women aged less than 30 years were adequately active. The cohort of mothers in the current study was mainly comprised of older mothers; nevertheless the data did not show any association between age and physical activity behaviour.

In the current study, associations between the exercise stage of change variable and physical activity level were identified. The exercise stage indicated by the participants was significantly associated with their physical activity level. For example, mothers who indicated that they were in the maintenance phase were 36.8 times more likely to be classified as being active than those in the pre-contemplation stage. In addition, mothers who were above the median physical activity score were more likely to attain a higher level in the Exercise Stages of Change Construct. In total, $48.2 \%$ of this sample 


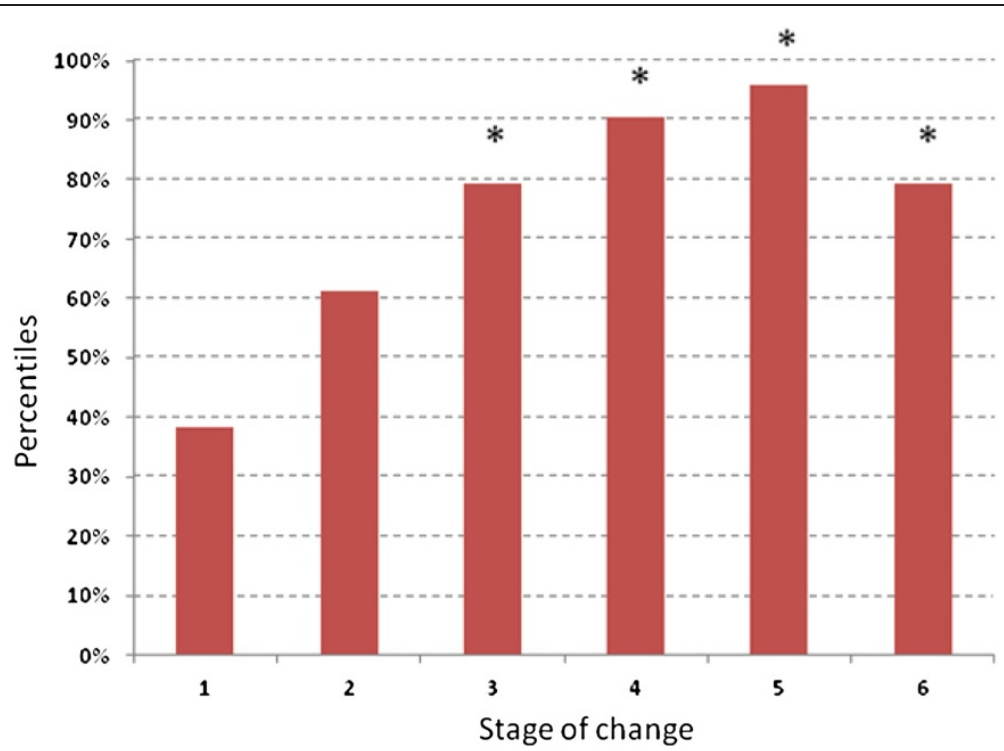

Figure 1 Percentiles of physically active mothers with young children within Exercise Stages of Change construct. Note: * denotes that the exercise stage of change was significantly different $(p<0.01)$ compared to stage one.

reported being in the action or maintenance phase. A similar correlation was reported by Fahrenwald \& Walker (2003) [41]. There is limited Australian data available to make comparisons, nevertheless the results from the current study indicate a more active sample than reported by Keller et al. [26] with only $13 \%$ of their cohort reporting regular participation in exercise. The current results also indicated that a high proportion of mothers were in the relapse stage, suggesting that while the majority of this sample were active, many struggled to maintain these levels due to competing demands when raising children.

Information about the current physical activity behaviour of participants and their stage of change is valuable. By utilising this construct during the needs analysis stage, the results can confidently assist program planners to develop and target relevant strategies by encouraging those in the maintenance stage to remain active and supporting those who are inactive to become active.

The results from this study also found links between self-efficacy for physical activity as well as partner support for physical activity. Mothers who had higher self-efficacy and partner support for physical activity were significantly more likely to be classified as being active compared to those who were inactive. These results were replicated when the second definition for physical activity status was included in the analysis (above or below the median physical activity score). Nevertheless, an association between social support from friends and other family members with physical activity was only found when using the 'above and below the median' definition. An association between social support for exercise and personal self-efficacy for physical activity has been discussed in previous research. Among a sample of mothers with young children, intervention strategies aimed at increasing partner support and self-efficacy were successful in helping to improve physical activity levels within the sample [13]. Hinton and Olson (2001) assessed psychosocial measures among women at 12months post-partum and found that higher self-efficacy for exercise as well as a greater intention to exercise resulted in healthier levels of physical activity [42]. An association between self-efficacy and levels of physical activity was also reported by Fahrenwald et al. [28] and Miller and Brown [29]. By confirming an association between physical activity, social support and self-efficacy among a sample of mothers, practitioners working on interventions with these groups should aim to identify current support and self-efficacy levels and include intervention strategies that aim to improve these measures.

A limitation of the current study is that the MET.mins method can overestimate energy expenditure depending on age and weight [43]. The method in the current study was used to make comparisons to previous research [17,32]. Objective physical activity measurements for evaluation were not used in this study due to time and financial constraints as well as due to the barriers associated with the target group discussed in a previous publication [15]. Items used $[30,31]$ have been recognised as being appropriate to assess physical activity levels [30].

The identified results are specific to mothers attending WA playgroups. With over 16,000 families' involved with Playgroup WA, the playgroup venue provides an established and accessible setting where health professionals can easily access mothers and their young children. 


\section{Conclusion}

Despite having higher physical activity levels, it appears many mothers with young children do need to overcome various barriers to engage in regular physical activity. The results from this study confirm the usefulness of the stages of change measure in that can be utilised by health promotion practitioners to identify physical activity behaviour and inform appropriate intervention strategies, specifically in playgroup settings. Interventions aimed at improving physical activity levels in mothers with young children should consider the relevance of the Stages of Change Construct as well as the need to strengthen self-efficacy and social support.

\section{Abbreviations \\ WHO: World Health Organization; WA: Western Australian \\ TTM: Transtheoretical Model; IPAQ-SV: International Physical Activity Questionnaire-Short Version; MET: Metabolic equivalent of task; SES: Socio-economic level; SEIFA: Socio-economic indexes for areas; SPSS: Statistical Package for Social Sciences; BMI: Body mass index.}

\section{Competing interests}

The authors declare that there are no competing interests.

\section{Authors' contributions}

CJ planned and implemented the research and wrote the first draft of the paper. JJ assisted with the planning of the research was the second reviewer of the paper. SD assisted with the planning and data analysis. PH, AM, ASA and $\mathrm{APH}$ assisted with the planning of the research and reviewed the paper. All authors read and approved the final manuscript.

\section{Acknowledgements}

This study was supported by the following organisations: Healthway; Sidney Myer Health Fund; Playgroup WA (Inc); WA Centre for Health Promotion Research; and the Centre for Behavioural Research in Cancer Control, supported by the Cancer Council (WA).

\section{Author details}

${ }^{1}$ Western Australian Centre for Health Promotion Research, School of Public Health, Curtin University, Western Australia, Perth, Australia. ${ }^{2}$ Centre for Behavioural Research in Cancer Control, Curtin University, Western Australia, Perth, Australia. ${ }^{3}$ Curtin Health Innovation Research Institute, Curtin University, Western Australia, Perth, Australia. ${ }^{4}$ Mater Mother's Hospital, Mater Medical Research Institute and Griffith Health Institute, Griffith University, Queensland, Nathan, Australia. ${ }^{5}$ Centre for Public Health Nutrition Research, University of Dundee, Dundee, UK.

Received: 26 April 2012 Accepted: 17 July 2013

Published: 29 July 2013

\section{References}

1. U.S. Department of Health and Human Services: Physical activity and health a report of the Surgeon General. Atlanta: Department of Health and Human Services, Centers for Disease Control and Prevention, National Center for Chronic Disease Prevention and Health Promotion; 1996.

2. World Health Organization: Global Recommendations on Physical Activity for Health. Switzerland: World Health Organisation; 2010.

3. Department of Health and Ageing: National Physical Activity Guidelines for Adults. Canberra: Australian Government; 1999.

4. U.S. Department of Health and Human Services: 2008 Physical Activity Guidelines for Americans. Washington D.C: Department of Health and Human Services; 2008.

5. Mottola MF: Exercise in the postpartum period: practical applications. Curr Sports Med Rep 2002, 1:362-368.

6. Rooney B, Schauberger C: Excess pregnancy weight gain and long-term obesity: One decade later. Obstet Gynecol 2002, 100:245-252.
7. Calfas K, Marcus B: Postpartum weight retention: a mother's weight to bear? Am J Prev Med 2007, 32:356-357.

8. Janney C, Zhang D, Sowers M: Lactation and weight retention. Am J Clin Nutr 1997, 66:1116-1124.

9. Schmitt NM, Nicholson WK, Schmitt J: The association of pregnancy and the development of obesity - results of a systematic review and metaanalysis on the natural history of postpartum weight retention. Int J Obes 2007, 31:1642.

10. Kac G, Benicio MH, Velasquez-Melendez G, et al: Breastfeeding and postpartum weight retention in a cohort of Brazilian women. Am J Clin Nutr 2004, 79:487-493.

11. Öhlin A, RÖssner S: Trends in eating patterns, physical activity and socio-demographic factors in relation to postpartum body weight development. Br J Nutr 1994, 71:457-470.

12. Australian Bureau of Statistics: National Health Survey: Summary of results, 2007-2008. Canberra: Commonwealth of Australia; 2010.

13. Miller $Y$, Trost S, Brown W: Mediators of physical activity behavior change among women with young children. Am J Prev Med 2002, 23(Suppl 1):98-103.

14. Centers for Disease Control and Prevention, Division of Nutrition, Physical Activity and Obesity, National Center for Chronic Disease Prevention and Health Promotion: U.S. Physical Activity Statistics. http://www.cdc.gov/ nccdphp/dnpa/physical/stats/.

15. Jones $C$, Burns $S$, Howat $P$, et al: Playgroups as a setting for nutrition and physical activity interventions for mothers with young children: exploratory qualitative findings. Health Promot J Aust 2010, 21:92.

16. Ball K, Crawford D, Warren N: How feasible are healthy eating and physical activity for young women? Public Health Nutr 2004, 7:433-441

17. Bell S, Lee C: Emerging adulthood and patterns of physical activity among young Australian women. Int J Behav Med 2005, 12(4):227-235.

18. Brown P, Brown W, Miller $Y$, et al: Perceived constraints and social support for active leisure among mothers with young children. Leisure Sci 2001, 23:131-144.

19. Andajani-Sutjahjo S, Ball K, Warren N, et al: Perceived personal, social and environmental barriers to weight maintenance among young women: a community survey. Int J Behav Nutr Phys Act 2004, 1:15.

20. Peterson $\mathrm{K}$, Sorensen $\mathrm{G}$, Pearson $\mathrm{M}$, et al: Design of an intervention addressing multiple levels of influence on dietary and activity patterns of low-income, postpartum women. Health Educ Res 2002, 17:531-540.

21. Everson K, Moos M, Carrier K, et al: Perceived barriers to physical activity among pregnant women. Maternal Child Health J 2009, 13:364-375.

22. Lewis B, Ridge D: Mothers reframing physical activity: family oriented politicism, transgression and contested expertise in Australia. Soc Sci Med 2005, 60:2295-2306

23. Moore LL, Lombardi DA, White MJ, et al: Influence of parents' physical activity levels on activity levels of young children. J Pediatr 1991, 118:215-219.

24. Hesketh K, Campbell K, Crawford D, et al: Associations between a mother's own activity levels and her self efficacy and intentions for her child's physical activity. J Sci Med Sport 2010, 12(Suppl 2):198.

25. Booth ML, Macaskill P, Owen N, et al: Population prevalence and correlates of stages of change in physical activity. Health Educ Behav 1993, 20:431-440.

26. Keller C, Allan J, Tinkle MB: Stages of change, processes of change, and social support for exercise and weight gain in postpartum women. J Obstet Gynecol Neonatal Nurs 2006, 35:232-240.

27. Krummel DA, Semmens E, Boury J, et al: Stages of change for weight management in postpartum women. J Am Diet Assoc 2004, 104:1102-1108.

28. Fahrenwald N, Atwood J, Walker S, et al: A randomized pilot test of "moms on the move": A physical activity intervention for WIC mothers. Ann Behav Med 2004, 27:82-90

29. Miller $Y$, Brown W: Determinants of active leisure for women with young children-an "ethic of care" prevails. Leisure Sci 2005, 27:405-420.

30. Craig C, Marshall A, Sjostrom M, et al: International physical activity questionnaire: 12-country reliability and validity. Med Sci Sports Exerc 2003, 35:1381-1395.

31. Health Outcomes Assessment EB: Analysis and Performance Reporting Directorate, Information and Performance Division, Department of Health: The WA Health and Wellbeing Surveillance System (WAHWSS), Design and Methodology, Technical Paper Series No 1. Western Australia: Department of Health; 2005.

32. Brown WJ, Bauman AE: Comparison of estimates of population levels of physical activity using two measures. Aust N Z J Public Health 2000, 24:520-525. 
33. Glanz K, Rimer B, Lewis F: Health behaviour and health education: theory, research and practice. 3rd edition. San Fransisco: Jossey-Bass; 2002.

34. Prochaska J, DiClemente C, Norcross J: In search of how people change: Applications to addictive behaviors. Am Psychol 1992, 47:1102-1114.

35. Marcus B, Selby $V$, Niaura $S$, et al: Self-efficacy and the stages of exercise behavior change. Res Q Exer Sport 1992, 63:60.

36. McAuley E, Mihalko S: Advances in sport and exercise psychology measurement. Morgantown: Fitness Information Technology; 2003.

37. Sallis JF: The development of scales to measure social support for diet and exercise behaviors. Prev Med 1987, 16:825.

38. Australian Bureau of Statistics: Socio-economic indexes for areas (SEIFA), 2006. Canberra: Australian Bureau of Statistics; 2008.

39. Le M, Tran BN: Perinatal Statistics in Western Australia 2008: Twenty-sixth annual report of the Western Australian midwives notification system. Western Australia: Department of Health WA; 2010.

40. Lee PH, Macfarlane DJ, Lam TH, Stewart SM: Validity of the International Physical Activity Questionnaire Short Form (IPAQ-SF): A systematic review. International Journal of Behavioral Nutrition and Physical Activity 2011, 8:115.

41. Fahrenwald NL, Walker SN: Application of the transtheoretical model of behavior change to the physical activity of WIC mothers. Public Health Nurs 2003, 20:307-317.

42. Hinton PS, Olson CM: Postpartum exercise and food intake: the importance of behavior-specific self-efficacy. J Am Diet Assoc 2001, 101:1430-1437.

43. Byrne NM, Hills AP, Hunter GR, Weinsier RL, Schutz Y: Metabolic equivalent: one size does not fit all. J App/ Physiol 2005, 99:1112-1119.

doi:10.1186/1756-0500-6-300

Cite this article as: Jones et al:: Utility of stages of change construct in the planning of physical activity interventions among playgroup mothers. BMC Research Notes 2013 6:300.

\section{Submit your next manuscript to BioMed Central and take full advantage of:}

- Convenient online submission

- Thorough peer review

- No space constraints or color figure charges

- Immediate publication on acceptance

- Inclusion in PubMed, CAS, Scopus and Google Scholar

- Research which is freely available for redistribution 